\title{
Bacterial vaginosis: prevalence in outpatients, association with some micro-organisms and laboratory indices
}

\author{
L CRISTIANO, N COFFETTI, G DALVAI, L LORUSSO, M LORENZI
}

From U.S.S.L. no 26, Laboratory of Chemical-Clinical and Microbiological Analysis, Ospedale "Briolini", Gazzaniga (BG), Italy

SUMMARY Seven hundred and ninety three women were investigated, aged between 16 and 78 years, to evaluate the prevalence of bacterial vaginosis (BV) and some associated micro-organisms, and to discuss the significance of laboratory indices correlated to this pathology. BV was diagnosed on the basis of four distinct criteria: a positive result of the test for amines with $10 \% \mathrm{KOH}$ (odour-test), the presence of clue cells on fresh microscopic examination, a $\mathrm{pH}>4.5$ and direct Gram stain positive (the presence of more than 40 Gram negative or Gram variable coccobacilli per microscopic field by 1000 magnifications under oil immersion). The total prevalence of BV was $20.5 \%$ (163); similar percentages were found in both fertile and pregnant women, whereas a lower percentage $(12.7 \%)$ was found in menopausal women. Gardnerella vaginalis was present in $235(29.6 \%)$ of the 793 women, in $144(88.3 \%)$ of the 163 with BV and in $91(14.4 \%)$ of the 630 women without BV. Mobiluncus species was present in $8.2 \%(65)$ of the total population, in $38.6 \%(63)$ of the women with BV and only in two $(0.3 \%)$ of the women without BV. In the women with BV lower percentages were found for Trichomonas vaginalis, yeasts, Chlamydia trachomatis and Neisseria gonorrhoeae. The absence of a definite relationship between BV and cultural isolation of $G$ vaginalis is confirmed whereas the role played by Mobiluncus spp still has to be clarified. It is concluded that it is not necessary to screen with all four laboratory indices. Two positive indices from a panel of three (excluding pH $>4.5$ and direct Gram stain positive in the same panel) allows the correct diagnosis of $\mathrm{BV}$ in almost all cases.

Bacterial vaginosis (BV), a syndrome of probably mixed bacterial aetiology without signs of inflammation of the vaginal mucosa (also known as nonspecific vaginitis), has been studied over a long period to establish the aetiological role of a particular microorganism, Gardnerella vaginalis. Gardner and Dukes ${ }^{12}$ were the first to establish a connection between the micro-organism and the disorder over 30 years ago.

Although $G$ vaginalis has been biochemically identified in eight biotypes, ${ }^{3}$ there are still no definite findings and no clear pathogenicity for any of these in relation to $\mathrm{BV}$. The association, however, remains between the syndrome and the micro-organism (once called Haemophilus vaginalis or Corynebacterium vaginalis), and is confirmed in a number of studies. ${ }^{48}$

Address for reprints: Dr Leone Cristiano, Laboratorio Analisi Chimico-Cliniche e Microbiologiche, Ospedale "Briolini", Via Manzoni, 24025 Gazzaniga (BG), Italy

Accepted for publication 7 September 1989
In $\mathrm{BV}, G$ vaginalis is usually associated with bacteria which are mostly anaerobic, ${ }^{569-15}$ which suggests that this association on a symbiotic basis is the cause of the infection. ${ }^{6910}$

The lack of a precise aetiological reference and ignorance of the infective mechanism have created and continue to create confusion and uncertainty. In fact, studies are still commonly found with reference to isolation of $G$ vaginalis rather than to the pathology itself, ${ }^{16-19}$ or studies in which patient selection is only made on the basis of symptoms, ${ }^{18-19}$ despite the fact that well-defined diagnostic criteria for $\mathrm{BV}$ have been established which do not take either the symptoms or a specific micro-organism into consideration. ${ }^{20}$

These criteria, classified by Amsel et al ${ }^{7}$ on the basis of previous observations made by other authors, ${ }^{5921}$ are based on determination of the $\mathrm{pH}$ of the secretion ( $>4.5$ ), on the presence of a characteristic fishy smell produced by the reaction with $10 \% \mathrm{KOH}$, on the observation of clue cells on microscopic examination and on the physical characteristics of the vaginal 
secretion (homogeneity, consistency and colour).

This parameter has, however, shown notably subjective elements which have led to its replacement by the direct Gram stain of the secretion itself. ${ }^{8}$ Other methods have also been found ${ }^{910}$ which are useful in diagnosing $\mathrm{BV}$, but which are not practicable in normal laboratories.

From the epidemiologic point of view, BV has not been studied in depth and the data available at present are rather scarce. The aim of our study was to evaluate the prevalence of BV outpatients who underwent microbiological study of their vaginal secretion, regardless of their age and their physiological condition. The role of some micro-organisms and laboratory indices associated with the pathology are also discussed.

\section{Patients and methods}

\section{PATIENTS}

Seven hundred and ninety three consecutive female outpatients between 16 and 78 years of age, who were referred to our laboratory by their family doctor, were examined over a period of three years (January 1985December 1987). None of these women had undergone any kind of vaginal and/or cervical screening before coming to our laboratory. Of 793 patients, 680 were at a fertile age, 32 were pregnant, 71 were in menopause and 10 had undergone hysterectomy. Almost all the patients were symptomatic and complained of one or more of the following symptoms: leucorrhoea, pruritis, burning, dyspareunia, pelvic pain, secretion with unpleasant odour; a small minority complained of urological symptoms or were sent by the urologist because their partners had urethritis or other inflammatory diseases of the urogenital tract.

A card was filled in for each patient with her personal details, anamnesis, symptoms and laboratory reports.

\section{LABORATORY METHODS}

The secretion was taken from the posterior vaginal fornix with a cotton swab, and was placed directly on Agar Sabouraud culture to look for yeasts, on human blood agar with the addition of gentamycin sulphate, nalidixic acid and anfotericine B (Gardnerella vaginalis selective supplement-OXOID) for isolation of $G$ vaginalis and on sheep blood agar without inhibitors. The latter was used as free growth culture. The plates of human agar blood and sheep blood agar were incubated for 48 hours at $37^{\circ} \mathrm{C}$ in candle jar, whereas the Sabouraud agar plate was incubated for 24-48 hours at $37^{\circ} \mathrm{C}$ (in air).

The yeasts which produced germinating tubes after 3 hours' incubation in human serum were identified as Candida albicans while the other yeasts were identified using the Mycotube system (Roche diagnostic). All the colonies which, after 48 hours' incubation on human blood agar, showed a diffused ring of beta-haemolysis, were presumably identified as $G$ vaginalis. They were negative catalase, did not produce haemolysis on sheep blood agar and on Gram testing showed up as small gram negative or gram variable $e^{22}$ rods (or coccobacilli). A swab with vaginal secretion was placed in a sterile test tube containing $0.5 \mathrm{ml}$ of saline so as to obtain a turbid solution, while a smear was prepared from another swab, which was then stained using the Gram method.

The $\mathrm{pH}$ was measured using Merck indicator strips. A drop of the secretion-saline mixture was used for the fresh microscopic examination $(400 \times)$ to look for clue cells, Trichomonas vaginalis and yeasts. Clue cells were identified as those vaginal epithelial cells with edges darkened by the presence of numerous small bacteria adhering to the surface.

Two drops of the same mixture of secretion and saline were put on a slide and after the addition of 1-2 drops of $10 \% \mathrm{KOH}$ the presence or absence of amines was determined (odour test); the result was considered positive if there was a characteristic fishy smell immediately after the addition of the $\mathrm{KOH}^{59}$

By means of microscopic examination after Gram staining $(1000 \times)$, the morphological characteristics of the bacteria were evaluated: the Gram positive rods, which were rather large and even pleiomorphous, were classified as belonging to the lactobaccilar flora, whilst the comma-shaped bacteria, which were either Gram negative or Gram variable, were presumptively identified as mobiluncus species.

The various morphological types present on the smear were counted and the results were expressed per microscopic field (pmf) as absent, rare $(<1 \mathrm{pmf}), 1+$ (1-10 pmf), $2+(11-40 \mathrm{pmf}), 3+(41-80 \mathrm{pmf})$ and $4+$ ( $>80 \mathrm{pmf}$ ). The results were recorded after taking the average number of bacteria (for each morphological type) found in five microscopic fields, using the areas of the smear with higher concentration to facilitate counting.

Secretions from the endocervix were collected on two alginate coated swabs and investigated for $N$ gonorrhoeae and $C$ trachomatis. When testing for $N$ gonorrhoeae the material was inoculated on Tayer Martin Agar immediately after the sample was taken and the medium was incubated in candle jar for 24-48 hours at $37^{\circ} \mathrm{C}$. Biochemical identification was made using the Neisseria system (Pasteur Institute). C trachomatis was looked for using the direct immunofluorescent method with monoclonal antibodies (Microtrak Syra-Bracco).

\section{DEFINITION OF BV}

The criteria used in this study to define BV can be 
considered a variation of those put forward by Amsel et al. ${ }^{7}$

All the patients who, irrespective of the presence or absence of traditional vaginal pathogens (Trichomonas vaginalis and Mycetes) and cervical pathogens ( $N$ gonorrhoeae and $C$ trachomatis), were found to have three out of four of the following laboratory indices simultaneously were considered to have BV:

A - Microscopic examination of the vaginal secretion after Gram staining showed a mixed bacterial flora with a number of gram negative or gram variable coccobacilli $>2+$ (direct Gram stain positive);

B - $\mathrm{pH}>4.5$;

C - Positive odour test (with $10 \% \mathrm{KOH}$ );

D - Presence of clue cells during the fresh microscopic examination $(400 \times)$.

\section{STATISTICAL METHODS}

The chi square test with Yates' correction and the exact test of Fisher ${ }^{23}$ were used to make the comparison between proportions, whereas calculation of the predictive values was made by applying Bayes' formula. ${ }^{24}$

\section{Results}

Out of 793 women investigated, 163 were found to have BV (20.5\%). In the groups of fertile and pregnant women, BV was found in $20.9 \%(142 / 680)$ and $21.9 \%$ $(7 / 32)$ respectively, whereas in the group of women in menopause, the frequency was found to be $12.7 \%$ $(9 / 71)$. These differences are not statistically significant. Of the 10 women who had undergone hysterectomy, five $(50 \%)$ had BV.

To check if there were differences in distribution of BV due to age in the group of fertile women, the patients were divided into six age groups, each with a span of five years, except for the last one (16-20, $21-25,26-30,31-35,36-40,>40)$. Frequency of BV found was $22.9 \%(11 / 48), 19.5 \%(36 / 185), 17 \cdot 5 \%$ (31/177). $22 \cdot 4 \%$ (26/116), $21 \cdot 4 \%(15 / 70)$ and $27 \cdot 4 \%$

Table 1 Association of micro-organisms isolated with bacterial vaginosis ( $B V$ )

\begin{tabular}{lccccc}
\hline & \multicolumn{2}{c}{$\begin{array}{l}\text { Women with } B V \\
(n=163)\end{array}$} & & \multicolumn{2}{c}{$\begin{array}{l}\text { Women without BV } \\
(n=630)\end{array}$} \\
\cline { 2 - 3 } \cline { 5 - 6 } Micro-organism & No & $\%$ & & No & $\%$ \\
\hline Gardnerella vaginalis & 144 & 88.3 & & 91 & 14.4 \\
Mobiluncus species* & 63 & 38.6 & & 0.3 \\
Trichomonas vaginalis & 19 & 11.6 & & 44 & 7.0 \\
Yeastst & 9 & 5.5 & & 124 & 19.7 \\
Chlamydia trachomatis & $8 / 151$ & 5.3 & & $5 / 600$ & 0.8 \\
Neisseria gonorrhoeae & $1 / 151$ & 0.7 & & $2 / 600$ & 0.3
\end{tabular}

*Identification on direct Gram strain smear $(1000 \times)$.

†Candida albicans 112 strains, Candida species 21 strains.
Table 2 Frequency of findings of combinations of the laboratory indices* used to diagnose the 163 cases of bacterial vaginosis

\begin{tabular}{llrr}
\hline Combinations & & No & $\%$ \\
\hline A + B + C + D & & 108 & 66.3 \\
A + B + C & (clue cells absent) & 18 & $11 \cdot 0$ \\
A + B + D & (negative odour test) & 28 & $17 \cdot 2$ \\
A + C + D & (pH<4.5) & 9 & $5 \cdot 5$ \\
B + C + D & (direct Gram stain negative) & 0 & 0.0 \\
\hline
\end{tabular}

*A = direct Gram stain positive. $\mathrm{B}=\mathrm{pH}>4.5 . \mathrm{C}=$ Positive odour test. $\mathrm{D}=$ Clue cells present.

(23/84) respectively. The difference between the various age groups is not statistically significant.

Out of all the patients investigated, $G$ vaginalis was found in $235(29.6 \%)$, yeasts in $133(16.8 \%)$, Trichomonas vaginalis in $63(7.9 \%)$ and Mobiluncus species in $65(8 \cdot 2 \%)$.

At cervical level, out of 751 women $C$ trachomatis was found in $13(1.7 \%)$ and $N$ gonorrhoeae in three (0.4).

The association between the single micro-organisms and BV is shown in table 1.

$G$ vaginalis and Mobiluncus spp were found simultaneously in $36.8 \%(60)$ of the 163 women with BV. In these women, when Mobiluncus spp was found with Gram staining, a positive culture for $G$ vaginalis followed; this occurred in $95.2 \%(60 / 63)$ of the cases.

Table 2 shows the percentages of combinations of the laboratory indices used to define BV: the most frequent finding $(66.3 \%)$ was the one including all four, whereas the least frequent was where the $\mathrm{pH}$ was lower than or equal to 4.5 .

The combination of indices $B+C+D$, which foresees a microscopic examination with a number of gram negative or gram variable coccobacilli $<2+$ (direct Gram stain negative), was never found.

Table 3 shows how patients not affected by BV very

Table 3 Frequency of finding two laboratory indiices only in 630 patients classified as not affected by bacterial vaginosis $(B V)$ according to the criteria used

\begin{tabular}{lcc}
\hline $\begin{array}{l}\text { Combination of two } \\
\text { laboratory indices }\end{array}$ & No & $\%$ \\
\hline A + B & 47 & $7 \cdot 46$ \\
A + C & $1 \dagger$ & $0 \cdot 16$ \\
A + D & 2 & $0 \cdot 32$ \\
B + C & 1 & $0 \cdot 16$ \\
C + D & 1 & $0 \cdot 16$ \\
\end{tabular}

*Criteria for the diagnosis of BV: simultaneous finding of 3 out of 4 of the following laboratory indices: A) direct Gram stain positive, B) $\mathrm{pH}>4.5, \mathrm{C}$ ) positive odour test, D) clue cells present. †Patient having had hysterectomy with presence of Mobiluncus species, doubtful presence of clue cells and with $\mathrm{pH}=4 \cdot 5$. 
rarely have association of two laboratory indices (except the A + B combination).

In this study two symptoms reported by the patients at the time of swab-taking were also taken into consideration: leucorrhea and the unpleasant smell of the secretion. $76 \cdot 1 \%(124 / 163)$ women with BV and $63 \%(397 / 630)$ without BV (p < 0.01) complained of leucorrhea, whilst $14 \cdot 7 \%(24 / 163)$ of the women with BV and only $1.3 \%(8 / 630)$ of those without BV $(p<0.001)$ complained of discharge with an unpleasant smell.

\section{Discussion}

A positive direct Gram stain of vaginal secretion, $\mathrm{pH}>4.5$, positive odour test and the presence of clue cells are the laboratory indices used by us at present for diagnosis of BV. This diagnosis does not take into account the symptoms, because of their poor specificity or sensitivity and because of the high percentage of women with asymptomatic BV. ${ }^{70}$ The data given in literature available at present, regarding the prevalence of the pathology, are not very extensive and often cannot be compared, in particular owing to the different methodological approach used in patient selection. However, BV is probably the most common vaginal infection in countries with high socio-economic development. Amsel et $\mathrm{al}^{7}$ reported a prevalence of about $20 \%$ of women attending a gynaecological clinic. Gravett $e t$ al $^{25}$ indirectly diagnosed BV using liquid-gas chromatography in $19 \%$ of 534 cases of pregnant women.

Using similar criteria to ours, Hallén et $a^{26}$ and Eschenbach et al ${ }^{27}$ find a frequency of $36 \%$ (164/455) and $33 \%(210 / 640)$ respectively in women attending an STD clinic.

A prevalence of $20.5 \%$ found in the population examined in this study therefore reflects the situation found elsewhere fairly accurately. The woman's age and physiological state do not seem to influence the onset of the pathology.

With regard to the isolation of $G$ vaginalis in the secretions of the population investigated, there is a higher percentage than reported by other authors ${ }^{16-182829}$ and this may be linked both to the different techniques used to isolate and identify the micro-organism, and to the different make-up of the population.

Different and more selective examination techniques $^{30}$ determine the increase in frequency of isolation of $G$ vaginalis, above all in women without BV. ${ }^{70}$

There remains the problem of the relationship between the occurrence of the micro-organism and the presence of the pathology under examination. Statistically we reached the conclusion that, whereas absence of $G$ vaginalis almost certainly excludes BV (negative predictive value $=96.6 \%$ ), the presence of the micro-organism is only predictive for the illness in $61.3 \%$ of cases. These values may be different in other laboratories since they are influenced both by the prevalence of BV and by the procedures used to cultivate and identify $G$ vaginalis.

However, our data confirms the findings of other authors, ${ }^{7}$ but it does not support those who claim ${ }^{17-18}$ that routine culture examination is necessary to isolate $G$ vaginalis in the study of genital infections.

Systematic and widespread testing for $G$ vaginalis can be useful but is not indispensable, and also proves costly both financially and in terms of work involved, since it does not represent the decisive index for diagnosis of BV.

Since data regarding the presence of $G$ vaginalis as a predictive index of a future onset of $\mathbf{B V}$ are also lacking, routine culture of the bacterium would only have an epidemiologic value.

In agreement with other authors, ${ }^{31}$ it is therefore necessary to reaffirm the concept of the non-existence of a definite identify between BV and $G$ vaginalis. Among the anaerobic bacteria most frequently associated with BV, apart from those belonging to the bacteroides and peptococcus genera, the "gram negative" vibrios are of particular interest today, placed systematically under the mobiluncus genus with the two species $M$ mulieris and $M$ curtisii. ${ }^{32}$

The role of these micro-organisms in determining BV is not known and the percentage of findings varies from $9.0 \%$ to $68.0 \%$ depending on the authors ${ }^{411-}$ $121533-35$ and the identification techniques used.

On the basis of our data (table 1), in agreement with Spiegel $e a^{15}$ and with Roberts $e t a^{35}$ the presence of mobiluncus spp in the vaginal secretion represents a high probability BV indicator (positive predictive value $=96.9 \%$ ), even if the absence of the microorganism does not exclude it (negative predictive value $=86.3 \%$ ). In the women with $B V$ it seems that even the genital mycoplasmas are found with greater frequency and/or in greater concentrations compared with the women without BV. ${ }^{525}$ Our preliminary data (unpublished) also show that there is an association between these micro-organisms and BV: this is more evident for M hominis (M hominis vs BV p < 0.001; $\mathrm{U}$. urealyticum vs BV $p<0.05$ ). However, the significance of their presence remains unknown and further studies are necessary to understand the role they play. Whether they represent an active component in determining BV or whether they are simple commensals or even whether they are an overriding infection is still to be clarified.

Microbiologically, the problem remains complex with many uncertainties. We do, however, agree with the opinion expressed by Hillier and Eschenbach ${ }^{31}$ about the need to re-examine the history of BV. 
Another factor of some importance, above all for the therapeutical implications which it may bring about, is the association between BV and the classical vaginal and cervical pathogens (table 1). The literature does not give many data about these mixed forms of infection and they therefore merit more detailed study. It is, however, advisable for a systematic search for these pathogens to be carried out in all laboratories.

Passing on to the reference indices, the importance of the clue cells, associated in various studies with BV, is noted. ${ }^{257837}$

We think that it is important to emphasise that this research should be carried out on fresh samples and not after Gram staining.

In the cases of $\mathrm{BV}$, the $\mathrm{pH}$ of the secretion is usually over 4.5. However, it is greater than 4.5 even in a notable percentage of women without BV so, rather than a true index of the syndrome, it should be considered a sign of abnormality. As can be deduced from table 3, the odour test was only rarely positive in the women without BV, confirming the data given in other studies, ${ }^{78}$ which classify it as an indicator test for the pathology. The direct Gram stain represents the other important index. Finding mixed bacterial flora consisting mainly of small gram negative or gram variable rods, each time associated with gram positive cocci and/or curved rods (Mobiluncus spp) and/or other gram negative bacteria, with simultaneous absence of lactobacillar flora, decidedly points to the diagnosis of BV. This microscopic picture is in sharp contrast to that seen in "normal" women where the smear is dominated by lactobacillar flora.

The fact that the B + C + D combination (table 2) was never found alone, but always associated with index $A$ shows that the latter is the most sensitive laboratory index. Apart from this, in the area of the pathology in question, it supplies more information than culture growth for $G$ vaginalis. In our opinion this research can be omitted since there is also the possibility in these cases of presumptive identification on a microscopic basis. ${ }^{8}$

The simultaneous finding of the four laboratory indices only occurs in $66 \%$ of cases. On the other hand, percentages varying from $5.5 \%$ to $17 \%$ show the association of three indices (table 2). From re-examination of the data, we have also noted that the positive outcome of two out of four (excluding the A + B combination as deduced from table 3 ), is very rare in women without BV and this could mean that testing for all four laboratory indices is superfluous. In short, the use of a protocol which foresees the association of the odour test, the clue cell test and direct Gram stain or odour test, clue cell testing and measurement of the $\mathrm{pH}$, allow the laboratory and/or physician to diagnose BV just as efficiently and rapidly. At least two of these must be found to be simultaneously positive.
We thank the microbiology technicians V. Valota and E. Bonomi for their collaboration.

\section{References}

1 Gardner HL, Dukes CD. New Etiologic agent in non specific bacterial vaginitis. Science 1954;120:853.

2 Gardner HL, Dukes CD. A newly defined specific infection previously classified "non specific vaginitis". Am J Obstet Gynecol 1955;69:962-76.

3 Piot P, van Dyck E, Peeters M, Hale J, Totten PA, Holmes KK. Biotypes of Gardnerella vaginalis. J Clin Microbiol 1984; 20:677-9.

4 Spiegel CA, Amsel R, Holmes KK. Diagnosis of bacterial vaginosis by direct Gram stain of vaginal fluid. J Clin Microbiol 1983;18:170-7.

5 Pheifer TA, Forsyth PS, Durfee MA, Polock HM, Holmes KK. Non specific vaginitis; role of Haemophilus vaginalis and treatment with metronidazole. N Engl J Med 1978;298: 1429-34.

6 Taylor E, Blackwell AL, Barlow D, Phillips I. Gardnerella vaginalis, anaerobes, and vaginal discharge. Lancet 1982; 91:1376-9.

7 Amsel R, Totten PA, Spiegel CA, Chen KCS, Eschenbach DA, Holmes KK. Non specific vaginitis: dignostic criteria and microbial and epidemiologic associations. Am J Med 1983; 74:14-22.

8 Cristiano L, Lorenzi M. Vaginiti non specifiche e "Gardnerella vaginalis": considerazioni metodologiche ed epidemiologiche su 328 casi. Quad Sclavo Diagn 1986;22:398-411.

9 Chen KCS, Forsyth PS, Buchaman TM, Holmes KK. Amine content of vaginal fluid from untreated patients with nonspecific vaginitis. J Clin Invest 1979;63:828-35.

10 Spiegel CA, Amsel R, Eschenbach DA, Scoeknecht F, Holmes KK. Anaerobic bacteria of nonspecific vaginitis. $N$ Engl J Med 1980;303:601-7.

11 Hjeim E, Hallen A, Forsum U, Wallin J. Anaerobic curved rods in vaginitis. Lancet 1981;ii:1353-4.

12 Holst E, Skarin A, Mårdh PA. Characteristics of anaerobic comma-shaped bacteria recovered from the female genital tract. Eur J Clin Microbiol 1982;1:310-6.

13 Phillips J, Taylor E. Anaerobic curved rods in vaginitis. Lancet 1982;i:221.

14 Thomason JL, Schreckenberger PC, Spellacy WN, Riff LJ, Leben LK. Clinical and microbiological characterization of patients with nonspecific vaginosis associated with motile, curved anaerobic rods. $J$ Infect Dis 1984;149:801-9.

15 Spiegel CA, Eschenbach DA, Amsel R, Holmes KK. Curved anaerobic bacteria in bacterial (nonspecific) vaginosis and their response to antimicrobial therapy. J Infect Dis 1983;148: 817-22.

16 Rota G, Perini M, Milanesi B, Peretti P. Applicazione di protocollo operativo per l'identificazione di Garnerella vaginalis nello studio delle vaginiti non specifiche. Boll Microbiologia e ind laboratorio 1986;2:71-4.

17 Rossi MR, Saletti G, Cirelli C, Visentini L, Ferrucci M, Carillo C, Soracco E. La diagnosi delle infezioni uruogenitali a trasmissione sessuale: attualità e prospettive. Microbiologia Medica 1986;:I:139-42.

18 Magliano EM, Garlaschi L, Varotto F, Clerici P. Aspetti microbiologici ed epidemiologici della infezioni da Gardenerella vaginalis. Igiene Moderna 1985;84:417-26.

19 Biondi M, Pulvirenti D, Cassaro N, Abbadessa MG. Frequenza di Gardnerella vagnalis, Candid spp. e Trichomonas vaginalis nel secreto vaginale in diverse condizioni patologiche e fisiologiche. Microbiologia Medica 1987;2:156-8.

20 Eschenbach DA, Bekassy S, Blackwell A, Ekgreen J, Hallen A, Wathne B. The diagnosis of bacterial vaginosis. Scand J Urol Nephrol 1984;Suppl 86:260-1. 
Bacterial vaginosis: prevalence in outpatients, association with some micro-organisms and laboratory indices 387

21 Gardner HL, Dukes CD. Haemophilus vaginalis vaginitis. Ann NY Acad Sci 1959;83:280-9.

22 Piot P, van Dyck E, Totten PA, Holmes KK. Identification of Gardnerella (Haemophilus) vaginalis. J Clin Microbiol 1982;15:19-24.

23 Armitage P. Statistica Medica. Milano: Feltrinelli, 1975:133-40.

24 Vecchio TJ. Predictive value of a single diagnostic test in unselected populations. N Engl J Med 1966;274:1171-3.

25 Gravett MG, Nelson HP, de Romen T, Critchlow C, Eschenbach DA, Holmes KK. Independent associations of bacterial vaginosis and Chlamydia trachomatis infection with adverse pregnancy outcome. JAMA 1986;256:1899-903.

26 Hallen A, Pahlson C, Forsum U. Bacterial vaginosis in women attending STD clinic: Diagnostic criteria and prevalence of Mobiluncus spp. Genitourin Med 1987;63:386-9.

27 Eschenbach DA, Hillier S, Critchlow C, Stevens C, de Rouen T, Holmes KK. Diagnosis and clinical manifestations of bacterial vaginosis. Am J Obstet Gynecol 1988;158:819-28.

28 Leone F, Morandotti S, Nacci A, Lepera C, Mazzella P. Sulla incidenza di Gardnerella vaginalis in un elevato numero di pazienti ambulatoriali. Igiene Moderna 1985;83:842-8.

29 Bramley HM, Dixon RA, Jones BM. Haemophilus vaginalis (corynebacterium vaginale, Gardnerella vaginalis) in a family planning clinic. Br J Venereal Dis 1981;57:62-6.

30 Totten PA, Amsel R, Hale J, Piot P, Holmes KK. Selective differential human blood bilayer media for isolation of
Gardnerella (Haemophilus) vaginalis. $J$ Clin Microbiol 1982;15:141-7.

31 Hillier SL, Eschenbach DA. Bacterial vaginosis: role of Mobiluncus species. Infection Diseases Newsletter 1986;5:65-8.

32 Spiegel CA, Roberts M. Mobiluncus gen nov, Mobiluncus curtisii subsp curtisii sp nov, Mobiluncus curtisii subsp nov, and Mobiluncus mulieris sp nov, curved rods from the human vagina. Int J System Bacteriol 1984;34:177-84.

33 Durieux R, Dublanchet A. Les "vibrions" anaerobes del leucorrhées I: Technique d'isolement et sensibilité aux antibiotiques. Med Mal Infect 1980;10:109-15.

34 Skarin A, Mårdh PA. Comma-shaped bacteria associated with vaginitis. Lancet 1982;i:342-3.

35 Roberts MC, Hillier SL, Schoenknecht FD, Holmes KK. Comparison of Gram stain, DNA probe, and culture for the identification of species of Mobiluncus in female genital specimens. J Infect Dis 1985;152:74-7.

36 Paavonen J, Miettinen A, Stevens CE, Chen KCS, Holmes KK. Mycoplasma hominis in nonspecific vaginitis. Sex Transm Dis 1983;4:271-5.

37 Burmeister RE, Gardner HL. Vaginitis: diagnosis and treatment. Postgrad Med 1970;48:159-63.

38 Erkkola R, Larvinen H, Therho P, Neurman O. Microbial flora in women showing symptoms of nonspecific vaginosis: applicability of KOH test for diagnosis. Scand $J$ Infect Dis 1983;suppl 40:59-63. 